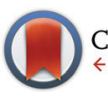

CrossMark \&lick for updates

Cite this: Org. Chem. Front., 2017, 4, 191

Received 12th October 2016, Accepted 2nd November 2016

DOI: $10.1039 / c 6 q 000625 f$

rsc.li/frontiers-organic

\title{
Direct observation and characterisation of 3-azido-2H-azirines: postulated, but highly elusive intermediates $\dagger+$
}

\author{
Kevin Weigand, § Neeraj Singh,§ Manfred Hagedorn and Klaus Banert*
}

For the first time, successful synthesis of an unknown class of compounds, 3-azido-2H-azirines, which are implicated as highly reactive intermediates in the thermolysis of the corresponding 1,1-diazidoethenes, has been performed. These elusive heterocycles have been detected and characterised by low-temperature NMR and in situ IR spectroscopy. Even the parent compound, 3-azido-2H-azirine, has been observed via low-temperature photolysis of 1,1-diazidoethene, as a highly reactive species with a half-life period of only 12 min at $-40^{\circ} \mathrm{C}$.

The azido group, although absent in natural products, is a highly versatile functionality which has found immense applications in various branches of chemistry, ${ }^{1}$ as well as biology ${ }^{2}$ and materials science. ${ }^{3}$ In particular, vinyl azides ${ }^{4}$ are useful starting materials for the synthesis of strained compounds, for example azirines, ${ }^{5}$ via photolysis or thermolysis and also for ring-enlarged heterocycles of synthetic and biological significance.

Although the parent compound $\mathbf{4}$ has not yet been reported and only four substituted representatives of 1,1-diazidoethenes, 1, 2a, $\mathbf{2 b}$ and 3, were mentioned in the literature, ${ }^{6}$ a rich chemistry, particularly with reactions of the push-pull olefin 1, was reported by Saalfrank ${ }^{7}$ and others ${ }^{8}$ (Scheme 1a). The treatment of $\mathbf{1}$ with different types of amines, for example, led to nitrogen heterocycles, such as $2 \mathrm{H}$-azirines, 1,2,3triazoles and tetrazoles, as depicted in scheme $1 b .^{7,9,10}$ Unimolecular reactions of $\mathbf{1}, \mathbf{2 a}$ and $\mathbf{2 b}$ induced by thermolysis or photolysis were also investigated intensively. ${ }^{7,8,10,11}$ In the case of substrate 1, extrusion of two or three molecules of dinitrogen and formation of the products 7 or 8 , respectively, were claimed (Scheme 1c). ${ }^{7,10,11}$ The thermal reaction of 1 was explained with the help of short-lived intermediate 5 and the subsequent cleavage of the $\mathrm{C}-\mathrm{C}$ bond in the three-membered ring, combined with the loss of a second molecule of dinitrogen. Finally, a two-step substitution of the cyano group by nucleophilic methanol should result in the generation of 7 .

Chemnitz University of Technology, Organic Chemistry, Strasse der Nationen 62, 09111 Chemnitz, Germany.E-mail: klaus.banert@chemie.tu-chemnitz.de $\dagger$ Dedicated to Prof. Adalbert Maercker on the occasion of his 85th birthday. \$Electronic supplementary information (ESI) available: Experimental procedures, spectroscopic data, and copies of NMR as well as IR spectra. See DOI: 10.1039/c6qo00625f

$\S$ These authors contributed equally to this work. a)

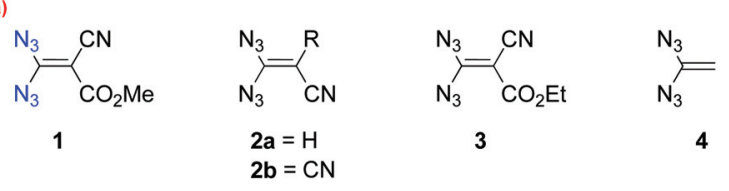

b)
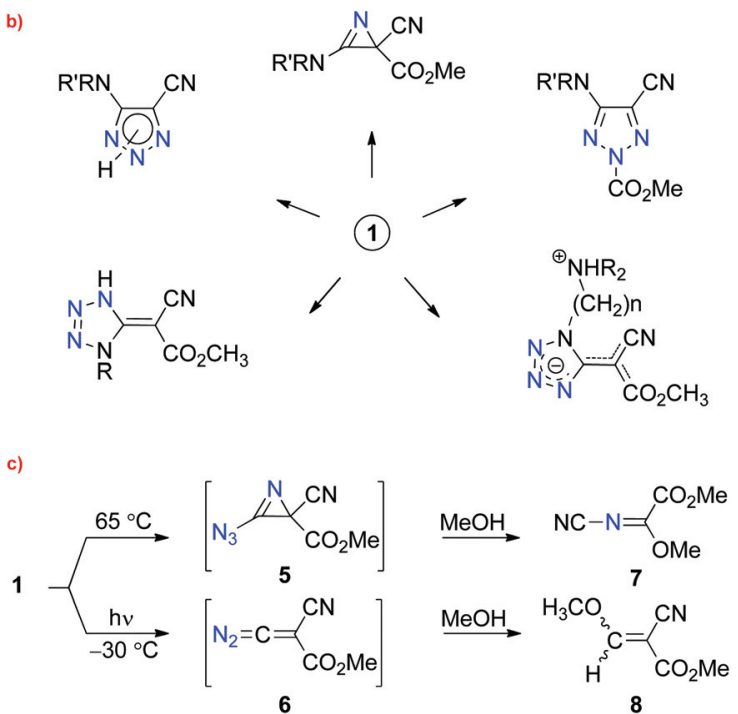

Scheme 1 (a) Reported (1, 2a, 2b and 3) and unknown (4) 1,1-diazidoethenes; (b) products prepared from compound 1; (c) proposed intermediates and products in the thermolysis and photolysis of 1 .

Irradiation of a solution of $\mathbf{1}$ in methanol at $-30{ }^{\circ} \mathrm{C}$ gave mainly "the thermal product" $7(70 \%)$ and the acrylic ester $\mathbf{8}$ as a side product $(30 \%){ }^{11}$ The diazo compound 6 and the derived carbene (vinylidene species) were discussed as shortlived intermediates in the surprising formation of $\mathbf{8}$. It is well 
known in the chemistry of vinyl azides that these substrates generally lead to high yields of the corresponding $2 \mathrm{H}$-azirines under low-temperature irradiation, whereas thermolysis of the same azides can give varying results: in some cases, heating a solution of a vinyl azide also afforded a high yield of the $2 \mathrm{H}$-azirine, but other such substrates avoided the thermal generation of these heterocycles and furnished quite different products. Thus, the reported unimolecular reactions of $\mathbf{1}$ are in contrast to the general rules of vinyl azide reactivity. ${ }^{4,5}$

Because 3-azido- $2 \mathrm{H}$-azirines are only postulated, ${ }^{7,10,11}$ however, never detected species, and intermediates of types $\mathbf{5}$ and 6 are obviously not only elusive, but also highly interesting, we judged low-temperature photolyses of diazide $\mathbf{1}$ and the parent compound $\mathbf{4}$ to be promising. We became further interested in such experiments, since we previously investigated the low-temperature irradiation of open-chain 1,2diazidoalkenes, ${ }^{12 a}$ which led to the first proof of long-sought 2-azido- $2 H$-azirines. ${ }^{12 b}$ Such short-lived species turned out to be intermediates in the known transformation of vicinal vinyl diazides into two nitrile fragments, that is accompanied by the cleavage of the $\mathrm{C}=\mathrm{C}$ bond and loss of two molecules of dinitrogen. In the case of 3-azido- $2 H$-azirines, the electron-donating properties of the azido group should be able to stabilize the azirine ring by reducing the electron deficiency at the $\mathrm{sp}^{2}$ carbon atom. This effect is well documented especially for 3-amino- $2 H$-azirines, which bear, however, a stronger donor. ${ }^{13}$ On the other hand, it is well known that the direct combination of strain resulting from small rings decreases the stability of azides.

Since light energy circumvents the problem of direct thermal agitation, we planned to irradiate $\mathbf{1}$ at low temperatures and to detect short-lived intermediate $\mathbf{5}$ by low-temperature NMR spectroscopy. Surprisingly, substrate $\mathbf{1}$ was not soluble in methanol at $-30^{\circ} \mathrm{C}$, and the same is true even for a $3: 1$ mixture of chloroform and methanol, although the solubility of $\mathbf{1}$ in neat chloroform is excellent. Thus, we photolysed a solution of 1 (30 mg) in deuterated chloroform $(0.75 \mathrm{~mL})$ with the help of a mercury high-pressure lamp (filter with $\lambda>$ $320 \mathrm{~nm}$ ), maintaining the temperature at $-60{ }^{\circ} \mathrm{C}$ through a cryostat. ${ }^{14}$ After $1 \mathrm{~h}$, low-temperature NMR analysis showed complete consumption of $\mathbf{1}$ and the formation of $2 \mathrm{H}$-azirine $\mathbf{5}$ with 78\% yield (Scheme 2 and Fig. 1). Under our conditions, prolonged irradiation (3-4 h) did not lead to a significant decay of azido compound $\mathbf{5}$, whereas decomposition of this compound occurred when the temperature of its solution was raised above $-10^{\circ} \mathrm{C}$. The structural proof of 5 is mainly based on the corresponding ${ }^{13} \mathrm{C} \mathrm{NMR}$ data and especially on the characteristic chemical shifts of the $2 H$-azirine unit with $\delta(\mathrm{C}-2)=32.8$ and $\delta(\mathrm{C}-3)=150.1$. The assignment of these signals was also supported by CIGAR experiments.

To provide further evidence of the structure of $\mathbf{5}$, we utilised strain-promoted alkyne-azide cycloaddition with the help of cyclooctyne to obtain the $1 H$-1,2,3-triazole 9. ${ }^{15,16}$ Although the product 9 showed limited stability at room temperature, most probably because of the electron-withdrawing properties of the triazolo unit, which increases the electron deficiency at C-3 of
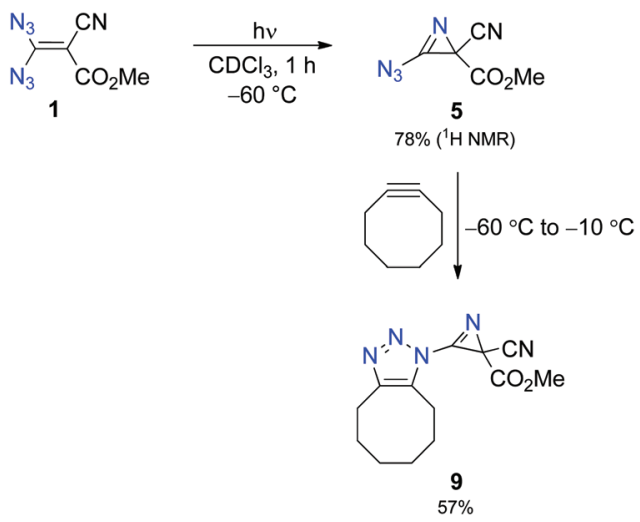

Scheme 2 Photolysis of 1 and subsequent reaction of the product 5 with cyclooctyne.

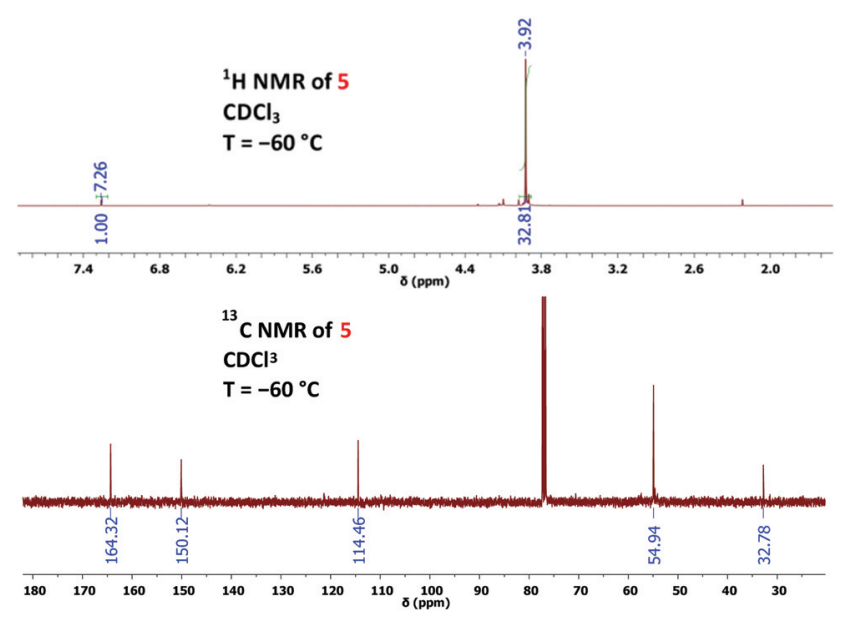

Fig. $1{ }^{1} \mathrm{H}$ NMR and ${ }^{13} \mathrm{C}$ NMR spectra of 5 .

the $2 \mathrm{H}$-azirine, we were able to isolate $\mathbf{9}$ as a straw-coloured oil in $57 \%$ yield, and this allowed complete characterisation of the trapping product. ${ }^{14}$ We also monitored the reaction of 5 with cyclooctyne in deuterated chloroform by using ${ }^{1} \mathrm{H}$ NMR spectroscopy to get an impression of the rate of this cycloaddition (Fig. 2). It turned out that the consumption of $\mathbf{5}$ was very slow at $-60{ }^{\circ} \mathrm{C}$, whereas a rapid formation of 9 was observed at $-20^{\circ} \mathrm{C}$.

Encouraged by successful characterisation of azirine 5, we were highly motivated to generate the parent compound, 3-azido-2H-azirine (16), which requires the synthesis of unknown 1,1-diazidoethene (4). Obviously, the latter compound cannot be prepared from 1,1-dichloroethene by nucleophilic substitution owing to the absence of electron-withdrawing groups that facilitate the access to diazides 1-3. Therefore, it seemed logical to utilise the chloroethane derivative $\mathbf{1 2}$ as a precursor for the desired diazide 4 (Scheme 3). However, all our attempts failed when we tried to directly transform chloroacetaldehyde into 12 by using well-established methods ${ }^{17}$ for the synthesis of geminal diazides from aldehydes. Subsequently, we employed the multifarious chemistry of 


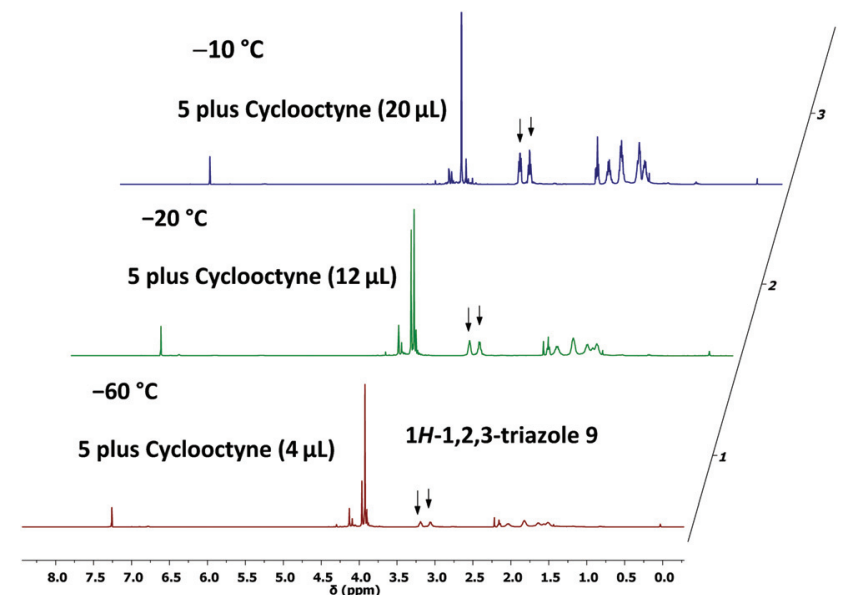

Fig. 2 Reaction of $\mathbf{5}$ with cyclooctyne (successively added in portions) at different temperatures.

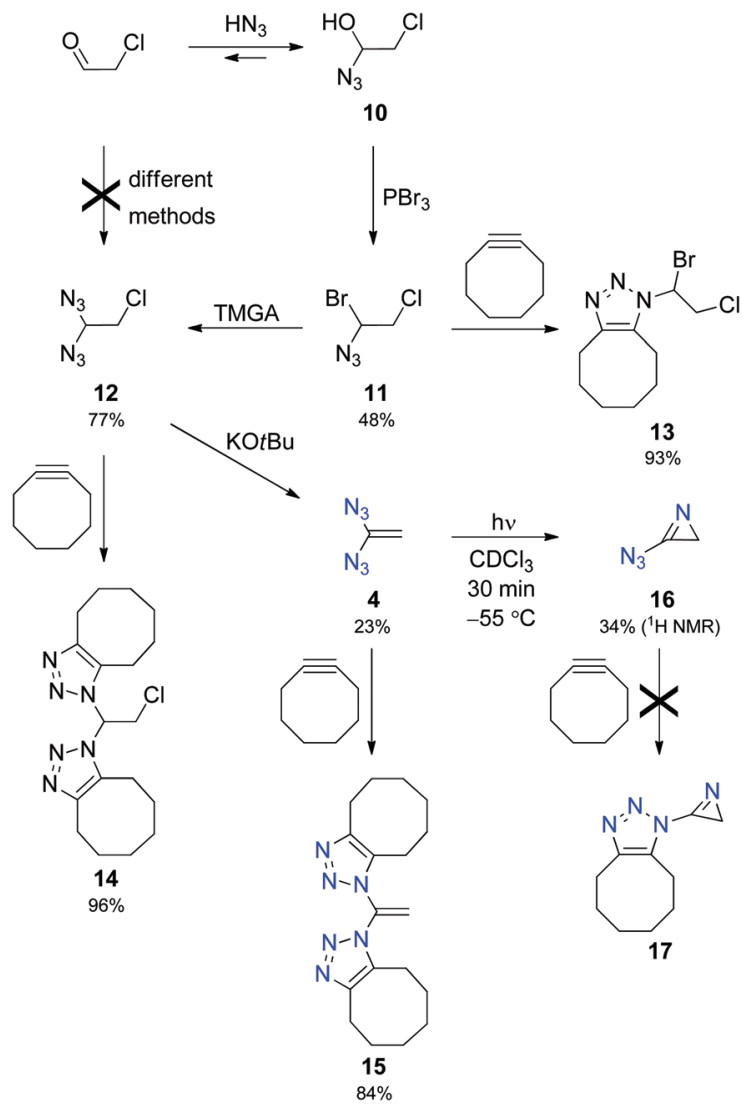

Scheme 3 Synthesis and reactions of 1,1-diazidoethene (4).

$\alpha$-azido alcohols ${ }^{6 a, 18}$ to prepare 12 in a three-step sequence. Thus, we treated chloroacetaldehyde with hydrazoic acid and reacted the resulting $\alpha$-azido alcohol 10 with phosphorus tribromide to obtain the intermediate product 11 with $48 \%$ yield based on the aldehyde. Selective nucleophilic substitution of 11 with the help of $N, N, N^{\prime}, N^{\prime}$-tetramethylguanidinium azide (TMGA) led to the desired diazide 12, which was transformed into 1,1-diazidoethene (4) in the presence of potassium tertbutoxide in diethyl ether. ${ }^{14}$

The azides 11, 12 and particularly 4 are dangerously explosive and should be handled and characterised in solution only, for example, by IR and NMR spectroscopy. Because of its substitution pattern, $\mathbf{4}$ is an electron-rich olefin as shown by an upfield shift of the NMR data with $\delta\left({ }^{13} \mathrm{C}\right)=85.3$ and $\delta\left({ }^{1} \mathrm{H}\right)=$ 4.40 measured for the $\mathrm{CH}_{2}$ group $\left(\mathrm{CDCl}_{3}\right)$. 1,1-Diazidoethene (4) has a limited stability at room temperature and a half-life period of $220 \mathrm{~min}$ at $40{ }^{\circ} \mathrm{C}$ in deuterated chloroform. With the help of cyclooctyne, explosive azides 4, 11 and 12 were transformed into the corresponding 1,2,3-triazoles 15, 13 and 14, respectively, and these heterocyclic derivatives were easily isolated and characterised. ${ }^{14,16}$

A solution of 4 in deuterated chloroform with diethyl ether as an internal standard was irradiated at $-55{ }^{\circ} \mathrm{C}$ using a mercury high-pressure lamp. After $30 \mathrm{~min}$, NMR low-temperature analysis showed the formation of 3-azido- $\mathrm{H}$-azirine (16) in $34 \%$ yield (Scheme 3 ). ${ }^{1} \mathrm{H}$ NMR spectroscopy at $-40{ }^{\circ} \mathrm{C}$ indicated a short half-life period of approximately $12 \mathrm{~min}$. Thus, 16 is very short-lived, and attempts to intercept this species in the presence of cyclooctyne did not lead to the desired cycloadduct 17. This unsuccessful experiment exhibits the limit of trapping unstable azides with the help of cyclooctyne.

The photolysis of $\mathbf{4}$ was also monitored with solutions of the diazide in toluene- $\mathrm{d}_{8}$ at $-55^{\circ} \mathrm{C}$ by using NMR spectroscopy (Fig. 3). The product 16 was identified by its high-field ${ }^{1} \mathrm{H}$ NMR signal at $\delta=1.49$ (singlet) and the characteristic ${ }^{13} \mathrm{C}$ NMR signals at $\delta=27.14(\mathrm{C}-2)$ and $\delta=161.25(\mathrm{C}-3)$, and the coupling constant ${ }^{1} J\left({ }^{13} \mathrm{C},{ }^{1} \mathrm{H}\right)=182 \mathrm{~Hz}$ is also typical of $2 \mathrm{H}$-azirines. ${ }^{5}$

Finally, we utilized in situ IR spectroscopy to detect the progress of the photochemical step $\mathbf{4} \rightarrow \mathbf{1 6}$ in deuterated chloroform at $-45{ }^{\circ} \mathrm{C}$ (Fig. 4). Signals at $2120 \mathrm{~cm}^{-1}$ (asym. $\mathrm{N}_{3}$ ), $1641 \mathrm{~cm}^{-1}(\mathrm{C}=\mathrm{C})$ and $1311 \mathrm{~cm}^{-1}$ (sym. $\mathrm{N}_{3}$ ) were assigned to the starting compound 4, whereas signals at $2148 \mathrm{~cm}^{-1}$ (asym. $\left.\mathrm{N}_{3}\right)$ and $1756 \mathrm{~cm}^{-1}(\mathrm{C}=\mathrm{N})$ were attributed to the product 16 .

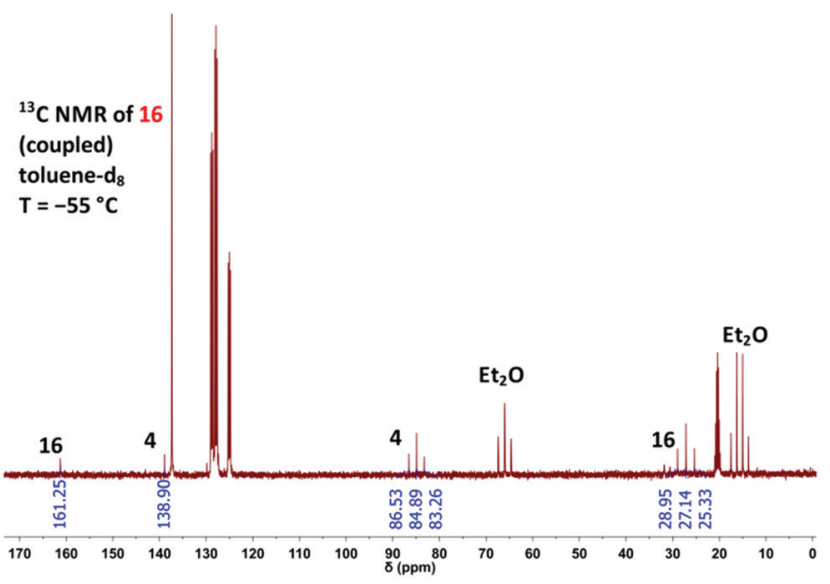

Fig. 3 Proton-coupled ${ }^{13} \mathrm{C}$ NMR spectrum measured at $-55^{\circ} \mathrm{C}$ during the photolysis of 4 in toluene- $d_{8}$ to generate 3 -azido- $2 H$-azirine (16). 


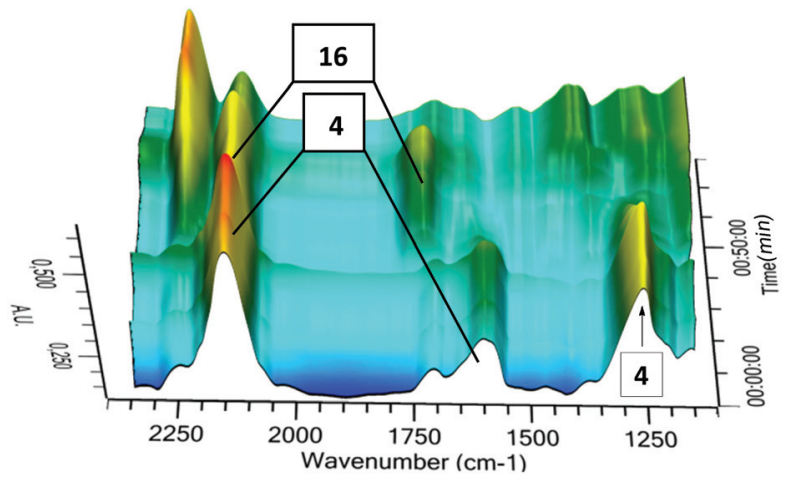

Fig. 4 IR spectra measured during the photolysis of 4 in $\mathrm{CDCl}_{3}$ at $-45{ }^{\circ} \mathrm{C}$; after $54 \mathrm{~min}$ of irradiation, the temperature was progressively raised to room temperature, which led to the decay of the photoproduct 16.

Our IR analysis confirmed the NMR results indicating that $\mathbf{1 6}$ is unstable even in solution at low temperatures. Furthermore, it is shown that the parent 3 -azido- $2 H$-azirine $\mathbf{1 6}$ is significantly less stable than the substituted heterocycle 5. Such an effect of substituents at the 2-position is well known for other $2 H$-azirines. ${ }^{5,19}$

\section{Conclusions}

In summary, we have demonstrated that the irradiation of 1,1-diazidoethenes $\mathbf{1}$ and $\mathbf{4}$ leads to 3-azido- $\mathrm{H}$-azirines 5 and 16, respectively. Although these photoproducts are highly unstable, their structures are unequivocally confirmed by lowtemperature NMR and IR spectroscopy as well as trapping reactions. This outcome confirms the general rule that photolysis of vinyl azides results in the formation of $2 \mathrm{H}$-azirines as primary products. ${ }^{4,5}$ Thus, we were not able to verify previous reports $^{11}$ from 1982 on the irradiation of 1 since we obtained different results.

Compounds 1, 4, 11 and 12 should be considered highly explosive, and effective safety measures should be taken when handling these substances in the pure state. We highly recommend the use of only dilute solutions in appropriate solvents. $^{20}$

\section{Acknowledgements}

This work is part 37 in the series "Reactions of Unsaturated Azides", for part 36, see ref. 6a. We thank Deutsche Forschungsgemeinschaft for financial support (BA 903/12/1-3).

\section{Notes and references}

1 (a) H. Tanimoto and K. Kakiuchi, Nat. Prod. Commun., 2013, 8, 1021-1034; (b) Organic Azides, Syntheses and Applications, ed. S. Bräse and K. Banert, Wiley, Chichester,
2010; (c) S. Bräse, C. Gil, K. Knepper and V. Zimmermann, Angew. Chem., Int. Ed., 2005, 44, 5188-5240; (d) E. F. V. Scriven and K. Turnbull, Chem. Rev., 1988, 88, 297-368.

2 X. Zhang and Y. Zhang, Molecules, 2013, 18, 7145-7159.

3 J.-F. Lutz, Angew. Chem., Int. Ed., 2007, 46, 1018-1025.

4 Reviews on vinyl azides: (a) B. Hu and S. G. DiMagno, Org. Biomol. Chem., 2015, 13, 3844-3855; (b) K. Banert, in Organic Azides, Syntheses and Applications, ed. S. Bräse and K. Banert, Wiley, Chichester, 2010, pp. 115-166; (c) S. J. Collier, in Science of Synthesis, ed. G. A. Molander, Thieme, Stuttgart, 2006, vol. 33, pp. 541-563; (d) K. Banert, in Houben-Weyl, ed. H. Kropf and E. Schaumann, Thieme, Stuttgart, 4th edn, 1993, vol. E15, pp. 818-875.

5 Reviews on $2 H$-azirines: (a) A. F. Khlebnikov and M. S. Novikov, Tetrahedron, 2013, 69, 3363-3401; (b) J. Backes, in Houben-Weyl, ed. D. Klamann, Thieme, Stuttgart, 4th edn, 1992, vol. E16c, pp. 321-369; (c) V. Nair, in The Chemistry of Heterocyclic Compounds, Small-Ring Heterocycles, ed. A. Hassner, John Wiley \& Sons, Inc., New York, 1983, vol. 42, part 1, pp. 215-332; (d) W. H. Pearson, B. W. Lian and S. C. Bergmeier, in Comprehensive Heterocyclic Chemistry II, ed. A. Padwa, Pergamon, New York, 1996, vol. 1A, pp. 1-60; (e) F. Palacios, A. M. Ochoa de Retana, E. Martinez de Marigorta and J. M. de los Santos, Eur. J. Org. Chem., 2001, 2401-2414; (f) T. L. Gilchrist, Aldrichimica Acta, 2001, 34, 51-55; $(g)$ K. M. L. Rai and A. Hassner, in Advances in Strained and Interesting Organic Molecules, ed. B. Halton, Jai, Greenwich, 2000, vol. 8, pp. 187-257.

6 Reviews including 1,1-diazidoethenes: (a) K. Banert, Synthesis, 2016, 2361-2375; (b) A. P. Häring and S. F. Kirsch, Molecules, 2015, 20, 20042-20062; (c) K. Banert, in Science of Synthesis, ed. A. de Meijere, Thieme, Stuttgart, 2006, vol. 24, pp. 747-765; (d) K. Banert, in Houben-Weyl, ed. H. Kropf and E. Schaumann, Thieme, Stuttgart, 4th edn, 1993, vol. E15, pp. 2348-2349.

7 R. W. Saalfrank and H. Maid, Chem. Commun., 2005, 59535967.

8 (a) H. K. Hall Jr., M. Ramezanian and F. D. Saeva, Tetrahedron Lett., 1988, 29, 1235-1238; (b) M. Ramezanian, A. B. Padias, F. D. Saeva and H. K. Hall Jr., J. Org. Chem., 1990, 55, 1768-1771; (c) B. Roekens, A. B. Padias and H. K. Hall Jr., J. Chem. Res., Synop., 1993, 162.

9 (a) R. W. Saalfrank, E. Ackermann, M. Fischer and U. Wirth, Chem. Ber., 1987, 120, 2003-2006; (b) R. Carrié, D. Danion, E. Ackermann and R. W. Saalfrank, Angew. Chem., Int. Ed. Engl., 1982, 21, 288; (c) R. Carrié, D. Danion, E. Ackermann and R. W. Saalfrank, Angew. Chem., Int. Ed. Engl., 1982, 668-674; (d) R. W. Saalfrank, M. Fischer, U. Wirth and H. Zimmermann, Angew. Chem., Int. Ed. Engl., 1987, 26, 1160-1161; (e) R. W. Saalfrank, U. Wirth and C.-J. Lurz, J. Org. Chem., 1989, 54, 4356-4359.

10 (a) R. W. Saalfrank and U. Wirth, Chem. Ber., 1989, 122, 519-522; (b) R. W. Saalfrank and U. Wirth, Chem. Ber., 1989, 122, 969-973; (c) R. W. Saalfrank, E. Ackermann, 
M. Fischer, U. Wirth and H. Zimmermann, Chem. Ber., 1990, 123, 115-120; (d) R. W. Saalfrank, C.-J. Lurz, J. Hassa, D. Danion and L. Toupet, Chem. Ber., 1991, 124, 595-608.

11 (a) R. Carrié, D. Danion, E. Ackermann and R. W. Saalfrank, Angew. Chem., Int. Ed. Engl., 1982, 21, 287; (b) R. Carrié, D. Danion, E. Ackermann and R. W. Saalfrank, Angew. Chem., Int. Ed. Engl., 1982, 660-667.

12 (a) J. R. Fotsing, M. Hagedorn and K. Banert, Tetrahedron, 2005, 61, 8904-8909; (b) K. Banert, J. R. Fotsing, M. Hagedorn, H. P. Reisenauer and G. Maier, Tetrahedron, 2008, 64, 5645-5648.

13 H. Heimgartner, Angew. Chem., Int. Ed. Engl., 1991, 30, 238-264.

14 See the ESI for further details.

15 (a) G. Wittig and A. Krebs, Chem. Ber., 1961, 94, 3260-3275; (b) N. J. Agard, J. A. Prescher and C. R. Bertozzi, J. Am. Chem. Soc., 2004, 126, 15046-15047.

16 For other examples of trapping highly unstable or explosive azides with the help of cyclooctyne, see: (a) K. Banert, M. Hagedorn, C. Liedtke, A. Melzer and C. Schöffler, Eur. J. Org. Chem., 2000, 257-267; (b) K. Banert and F. Köhler, Angew. Chem., Int. Ed., 2001, 40, 174-177; (c) K. Banert, Y.-H. Joo, T. Rüffer, B. Walfort and H. Lang,
Angew. Chem., Int. Ed., 2007, 46, 1168-1171; (d) K. Banert, Y.-H. Joo, T. Rüffer, B. Walfort and H. Lang, Tetrahedron Lett., 2010, 51, 2880-2882; (e) K. Banert, M. Hagedorn, J. Wutke, P. Ecorchard, D. Schaarschmidt and H. Lang, Chem. Commun., 2010, 46, 4058-4060; (f) K. Banert, R. Arnold, M. Hagedorn, P. Thoss and A. A. Auer, Angew. Chem., Int. Ed., 2012, 51, 7515-7518; (g) K. Banert, S. Richter, D. Schaarschmidt and H. Lang, Angew. Chem., Int. Ed., 2013, 52, 3499-3502; (h) K. Banert, M. Hagedorn, Z. Wu and X. Zeng, Molecules, 2015, 20, 21328-21335.

17 (a) H. Suzuki and C. Nakaya, Synthesis, 1992, 641-642; (b) K. Nishiyama, M. Oba and A. Watanabe, Tetrahedron, 1987, 43, 693-700; (c) H. Yanai and T. Taguchi, Tetrahedron Lett., 2005, 46, 8639-8643.

18 K. Banert, C. Berndt, S. Firdous, M. Hagedorn, Y.-H. Joo, T. Rüffer and H. Lang, Angew. Chem., Int. Ed., 2010, 49, 10206-10209.

19 For an example of such an effect, see: K. Banert, Tetrahedron Lett., 1985, 26, 5261-5264.

20 For potential hazards in handling hydrazoic acid and organic azides, see: T. Keicher and S. Löbbecke, in Organic Azides, Syntheses and Applications, ed. S. Bräse and K. Banert, Wiley, Chichester, 2010, pp. 3-27. 